\title{
Kinetics of Solid-State Reactive Diffusion in the (Sn-Ni)/Cu System
}

\author{
Misako Nakayama ${ }^{1}$ and Masanori Kajihara ${ }^{2, *}$ \\ ${ }^{1}$ Graduate School, Tokyo Institute of Technology, Yokohama 226-8502, Japan \\ ${ }^{2}$ Department of Materials Science and Engineering, Tokyo Institute of Technology, Yokohama 226-8502, Japan
}

\begin{abstract}
The kinetics of the solid-state reactive diffusion between $\mathrm{Sn}-\mathrm{Ni}$ alloys and pure $\mathrm{Cu}$ was experimentally observed to examine effects of addition of $\mathrm{Ni}$ into $\mathrm{Sn}$ on the growth behavior of compounds at the interconnection between the $\mathrm{Sn}$-base solder and the multilayer $\mathrm{Au} / \mathrm{Ni} / \mathrm{Cu}$ conductor during energization heating. In this experiment, sandwich $(\mathrm{Sn}-\mathrm{Ni}) / \mathrm{Cu} /(\mathrm{Sn}-\mathrm{Ni})$ diffusion couples with $\mathrm{Ni}$ concentrations of $y=0.01$ and 0.03 were isothermally annealed in the temperature range of $433-473 \mathrm{~K}$ for various periods up to $1152 \mathrm{~h}$, where $y$ is the mol fraction of Ni. After annealing, a compound layer consisting of $\mathrm{Cu}_{6} \mathrm{Sn}_{5}$ and $\mathrm{Cu}_{3} \mathrm{Sn}$ was recognized between the $\mathrm{Sn}-\mathrm{Ni}$ alloy and the $\mathrm{Cu}$ specimen in the diffusion couple. Here, the thickness of the $\mathrm{Cu}_{3} \mathrm{Sn}$ layer is smaller than that of the $\mathrm{Cu}_{6} \mathrm{Sn}_{5}$ layer. The $(\mathrm{Cu}, \mathrm{Ni})_{6} \mathrm{Sn}_{5}$ grains were transformed from

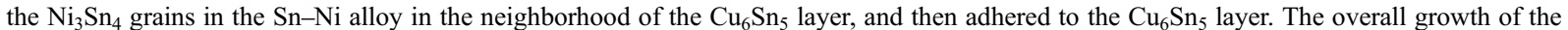
compound layer including the $(\mathrm{Cu}, \mathrm{Ni})_{6} \mathrm{Sn}_{5}$ grains is remarkably accelerated by the adhesion, but that of the compound layer excluding the $(\mathrm{Cu}, \mathrm{Ni})_{6} \mathrm{Sn}_{5}$ grains is slightly decelerated by the adhesion. The mean thickness of each layer increases in proportion to a power function of the annealing time. For annealing at $433-473 \mathrm{~K}$, the ratio between the thicknesses of the $\mathrm{Cu}_{6} \mathrm{Sn}_{5}$ and $\mathrm{Cu}_{3} \mathrm{Sn}$ layers is hardly affected by the addition of $\mathrm{Ni}$ into $\mathrm{Sn}$ up to $y=0.03$. [doi:10.2320/matertrans.M2014038]
\end{abstract}

(Received February 4, 2014; Accepted May 16, 2014; Published July 4, 2014)

Keywords: reactive diffusion, metallization, solder, conductor, intermetallic compounds

\section{Introduction}

Owing to high electrical conductivity, $\mathrm{Cu}$-base alloys are widely used as conductor materials in the electronics industry. If the $\mathrm{Cu}$-base conductor is interconnected with a Sn-base solder, $\mathrm{Cu}_{6} \mathrm{Sn}_{5}$ and $\mathrm{Cu}_{3} \mathrm{Sn}$ are formed at the interconnection between the conductor and the solder during soldering and then gradually grow during energization heating at solid-state temperatures. ${ }^{1-11)}$ Since the $\mathrm{Cu}-\mathrm{Sn}$ compounds are brittle and possess high electrical resistivities, their growth deteriorates the mechanical and electrical properties of the interconnection. To inhibit the formation of the compounds, the Cu-base conductor is usually plated with a $\mathrm{Ni}$ layer. However, $\mathrm{Ni}$ is not sufficiently corrosion resistant. Thus, the Ni layer is plated with a $\mathrm{Au}$ or Pd layer to improve corrosion resistance. ${ }^{12-15)}$

For the multilayer $\mathrm{Au} / \mathrm{Ni} / \mathrm{Cu}$ conductor with a thin $\mathrm{Au}$ layer, the Au layer quickly dissolves into a molten Sn-base solder during soldering, and then the Ni layer is contacted with the solder. Consequently, the Ni layer is directly reacted with the solder during solid-state energization heating. The solid-state reactive diffusion in the $\mathrm{Ni} / \mathrm{Sn}$ system was experimentally examined using sandwich $\mathrm{Sn} / \mathrm{Ni} / \mathrm{Sn}$ diffusion couples prepared by a diffusion bonding technique in a previous study. ${ }^{16)}$ In this experiment, the diffusion couples were isothermally annealed at temperatures of $T=433$ $473 \mathrm{~K}$. At the interface in the annealed diffusion couple, a layer of $\mathrm{Ni}_{3} \mathrm{Sn}_{4}$ was observed at $T=453-473 \mathrm{~K}$, but granular particles of $\mathrm{Ni}_{3} \mathrm{Sn}_{4}$ were recognized at $T=433 \mathrm{~K}$. The mean thickness of the $\mathrm{Ni}_{3} \mathrm{Sn}_{4}$ layer increases in proportion to a power function of the annealing time. The exponent of the power function is 0.46 and 0.41 at $T=453$ and $473 \mathrm{~K}$, respectively. The exponent smaller than 0.5 indicates that the growth of $\mathrm{Ni}_{3} \mathrm{Sn}_{4}$ is controlled by boundary and volume diffusion and grain growth occurs in $\mathrm{Ni}_{3} \mathrm{Sn}_{4}$. Although the growth of $\mathrm{Ni}_{3} \mathrm{Sn}_{4}$ may be accelerated by boundary diffusion,

*Corresponding author, E-mail: kajihara@materia.titech.ac.jp the overall growth rate is smaller for $\mathrm{Ni}_{3} \mathrm{Sn}_{4}{ }^{16)}$ than for $\mathrm{Cu}_{6} \mathrm{Sn}_{5}$ and $\mathrm{Cu}_{3} \mathrm{Sn}^{3,11)}$ As a consequence, the Ni layer works as a barrier against the reactive diffusion at the interconnection between the Sn-base solder and the multilayer $\mathrm{Au} /$ $\mathrm{Ni} / \mathrm{Cu}$ conductor with a thin $\mathrm{Au}$ layer during solid-state energization heating.

After prolonged energization heating, however, the $\mathrm{Ni}$ layer will be completely depleted by the growth of $\mathrm{Ni}_{3} \mathrm{Sn}_{4}$. Due to the depletion of the Ni layer, the Cu-base conductor is directly contacted with the solder. In such a case, the reactive diffusion between the conductor and the solder occurs at the interconnection. The solid-state reactive diffusion in the $\mathrm{Cu} / \mathrm{Sn}$ system was experimentally observed in a previous study. ${ }^{11)}$ In this experiment, like the Ni/Sn system, ${ }^{16)} \mathrm{Sn} / \mathrm{Cu} /$ $\mathrm{Sn}$ diffusion couples were prepared by a diffusion bonding technique and then isothermally annealed at $T=433-473 \mathrm{~K}$. At all the annealing temperatures, an intermetallic layer composed of $\mathrm{Cu}_{6} \mathrm{Sn}_{5}$ and $\mathrm{Cu}_{3} \mathrm{Sn}$ is formed at the original $\mathrm{Cu} /$ $\mathrm{Sn}$ interface in the diffusion couple. Also in this case, the intermetallic layer grows according to the power relationship. The exponent of the power function is close to 0.5 at $T=$ $473 \mathrm{~K}$ but becomes 0.37 and 0.43 at $T=433$ and $453 \mathrm{~K}$, respectively. Thus, in the $\mathrm{Cu} / \mathrm{Sn}$ system, ${ }^{11)}$ the growth of the intermetallic layer is controlled by volume diffusion at $T=473 \mathrm{~K}$ but by volume and boundary diffusion at $T=433$ and $453 \mathrm{~K}$. Therefore, the rate-controlling process of reactive diffusion varies depending on the annealing temperature and the metal system.

As previously mentioned, during prolonged energization heating, the $\mathrm{Ni}$ layer of the multilayer $\mathrm{Au} / \mathrm{Ni} / \mathrm{Cu}$ conductor is entirely consumed by the growth of $\mathrm{Ni}_{3} \mathrm{Sn}_{4}$, and then the $\mathrm{Cu}$-base conductor is reacted with the $\mathrm{Sn}$-base solder dispersed with $\mathrm{Ni}_{3} \mathrm{Sn}_{4}$. The dispersion of $\mathrm{Ni}_{3} \mathrm{Sn}_{4}$ in the solder may influence the kinetics of the reactive diffusion between the conductor and the solder at the interconnection. Unfortunately, however, reliable information on such influence is rather limited. To examine this influence, the kinetics of the solid-state reactive diffusion in the $(\mathrm{Sn}-\mathrm{Ni}) / \mathrm{Cu}$ system 
was experimentally observed at temperatures of $T=433$ $473 \mathrm{~K}$ using sandwich $(\mathrm{Sn}-\mathrm{Ni}) / \mathrm{Cu} /(\mathrm{Sn}-\mathrm{Ni})$ diffusion couples with $\mathrm{Ni}$ mol fractions of $0.01-0.03$ in the present study.

\section{Experimental}

Binary Sn-Ni alloys with $\mathrm{Ni}$ concentrations of $y=0.01$ and 0.03 were made as $25 \mathrm{~g}$ button ingots by argon arc melting from pure $\mathrm{Sn}$ and $\mathrm{Ni}$ with purities of 99.99 and $99.97 \%$, respectively, where $y$ is the mol fraction of Ni. Plate specimens with a size of $12 \mathrm{~mm} \times 5 \mathrm{~mm} \times 2 \mathrm{~mm}$ were prepared by cold rolling and spark erosion from the button ingots. The plate specimens were isothermally heated in an oil bath with silicone oil at $473 \mathrm{~K}$ for $2 \mathrm{~h}$, followed by water quenching. The two surfaces with an area of $12 \mathrm{~mm} \times 5 \mathrm{~mm}$ of each heated $\mathrm{Sn}-\mathrm{Ni}$ plate specimen were mechanically polished on \# 800 emery paper. One of the two polished surfaces was again mechanically polished on \# 1500-4000 emery papers until a depth of $100 \mu \mathrm{m}$ and then finished using diamond with a diameter of $1 \mu \mathrm{m}$.

Sheet specimens with a size of $20 \mathrm{~mm} \times 7 \mathrm{~mm} \times 0.2 \mathrm{~mm}$ were cut from a pure $\mathrm{Cu}$ commercial sheet with dimensions of $300 \mathrm{~mm} \times 100 \mathrm{~mm} \times 0.2 \mathrm{~mm}$ and purity of $99.96 \%$ and then separately annealed in evacuated silica capsules at $1173 \mathrm{~K}$ for $2 \mathrm{~h}$, followed by air cooling without breaking the capsules. The annealed sheet specimens were chemically polished in nitrohydrochloric acid for $60 \mathrm{~s}$.

After chemical polishing, a $\mathrm{Cu}$ sheet specimen was immediately sandwiched between the finished surfaces of two freshly prepared $\mathrm{Sn}-\mathrm{Ni}$ plate specimens in ethanol by the technique used in a previous study. ${ }^{11)}$ The sandwich ( $\mathrm{Sn}$ $\mathrm{Ni}) / \mathrm{Cu} /(\mathrm{Sn}-\mathrm{Ni})$ couples were completely dried and then heat treated for diffusion bonding in the oil bath at $433 \mathrm{~K}$, $453 \mathrm{~K}$ and $473 \mathrm{~K}$ for $12.5 \mathrm{~h}$. After the heat treatment, the diffusion couples were isothermally annealed at $433 \mathrm{~K}$, $453 \mathrm{~K}$ and $473 \mathrm{~K}$ for various times up to $1139.5 \mathrm{~h}$. The summation of the heat-treating and annealing times is hereafter merely called the annealing time $t$, and the annealing temperature is denoted by $T$. The chemical composition of the $\mathrm{Sn}-\mathrm{Ni}$ alloy is described as $\mathrm{Sn}-y \mathrm{Ni}$. The $\mathrm{Sn}-0.01 \mathrm{Ni}$ and $\mathrm{Sn}-0.03 \mathrm{Ni}$ alloys are designated alloys $\mathrm{N} 1$ and N2, respectively, and the diffusion couples with alloys N1 and N2 are called diffusion couples N1 and N2, respectively. Cross-sections of the annealed diffusion couple were mechanically polished using diamond with diameters of 15,3 and $1 \mu \mathrm{m}$, and then finished with an OP-S liquid manufactured by Struers Ltd. The microstructure of the cross-section was observed by differential interference contrast optical microscopy (DICOM). Concentrations of $\mathrm{Sn}, \mathrm{Ni}$ and $\mathrm{Cu}$ in each phase on the cross-section were measured by electron probe microanalysis (EPMA).

\section{Results and Discussion}

\subsection{Microstructure}

Typical DICOM images for the cross-section of diffusion couple N1 with $T=473 \mathrm{~K}$ and $t=144 \mathrm{~h}\left(5.18 \times 10^{5} \mathrm{~s}\right)$ are shown in Fig. 1. For each DICOM image in Fig. 1, the top and bottom regions are the $\mathrm{Sn}-\mathrm{Ni}$ alloy and the $\mathrm{Cu}$ specimen,
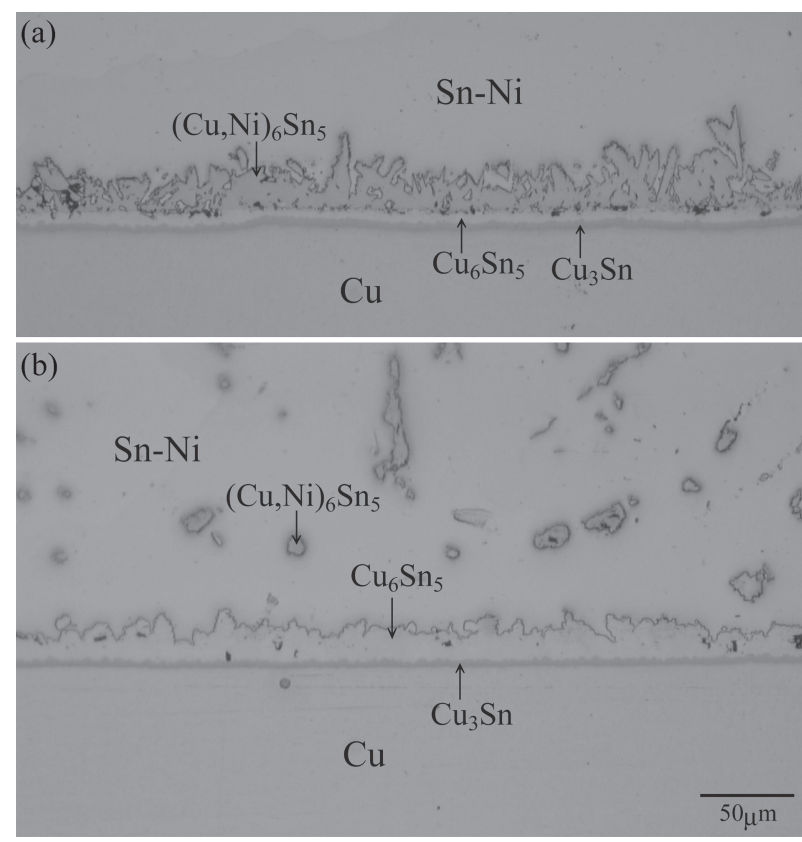

Fig. 1 DICOM images of diffusion couple N1 annealed at $T=473 \mathrm{~K}$ for $t=144 \mathrm{~h}\left(5.18 \times 10^{5} \mathrm{~s}\right)$ : (a) $(\mathrm{Cu}, \mathrm{Ni})_{6} \mathrm{Sn}_{5}, \mathrm{Cu}_{6} \mathrm{Sn}_{5}$ and $\mathrm{Cu}_{3} \mathrm{Sn}$ layers; and (b) $\mathrm{Cu}_{6} \mathrm{Sn}_{5}$ and $\mathrm{Cu}_{3} \mathrm{Sn}$ layers.

respectively. As can be seen, layers with different contrasts are formed at the original $(\mathrm{Sn}-\mathrm{Ni}) / \mathrm{Cu}$ interface. To identify each layer, concentration profiles of $\mathrm{Sn}, \mathrm{Ni}$ and $\mathrm{Cu}$ were measured by EPMA along the direction normal to the original interface. Results of the layers in Fig. 1(a) and 1(b) are indicated in Fig. 2(a) and 2(b), respectively. In Fig. 2, the ordinate and the abscissa show the mol fraction $y_{i}$ of component $i$ and the distance $x$ measured from an arbitrary origin, respectively, and open circles, rhombuses and squares represent the mol fractions $y_{\mathrm{Sn}}, y_{\mathrm{Ni}}$ and $y_{\mathrm{Cu}}$, respectively. In Fig. 2(b), the layers on the $\mathrm{Sn}-\mathrm{Ni}$ and $\mathrm{Cu}$ sides are $\mathrm{Cu}_{6} \mathrm{Sn}_{5}$ and $\mathrm{Cu}_{3} \mathrm{Sn}$, respectively. The thickness is much smaller for $\mathrm{Cu}_{3} \mathrm{Sn}$ than for $\mathrm{Cu}_{6} \mathrm{Sn}_{5}$. On the other hand, in Fig. 2(a), $(\mathrm{Cu}, \mathrm{Ni})_{6} \mathrm{Sn}_{5}$ is recognized on the $\mathrm{Sn}-\mathrm{Ni}$ side of the $\mathrm{Cu}_{6} \mathrm{Sn}_{5}$ layer. Here, the $\mathrm{Cu} / \mathrm{Cu}_{3} \mathrm{Sn}, \mathrm{Cu}_{3} \mathrm{Sn} / \mathrm{Cu}_{6} \mathrm{Sn}_{5}, \mathrm{Cu}_{6} \mathrm{Sn}_{5} /$ $(\mathrm{Cu}, \mathrm{Ni})_{6} \mathrm{Sn}_{5}$ and $(\mathrm{Cu}, \mathrm{Ni})_{6} \mathrm{Sn}_{5} / \mathrm{Sn}$ interfaces are denoted by interfaces $\mathrm{A}, \mathrm{B}, \mathrm{C}$ and $\mathrm{D}$, respectively. The thickness of the $\mathrm{Cu}_{6} \mathrm{Sn}_{5}$ layer is smaller in Figs. 1(a) and 2(a) with $(\mathrm{Cu}, \mathrm{Ni})_{6} \mathrm{Sn}_{5}$ than in Figs. $1(\mathrm{~b})$ and $2(\mathrm{~b})$ without $(\mathrm{Cu}, \mathrm{Ni})_{6} \mathrm{Sn}_{5}$. The EPMA measurement was conducted also for compound grains dispersed in the $\mathrm{Sn}-\mathrm{Ni}$ alloy of the diffusion couple shown in Fig. 1. Figure 2(c) indicates the result of a compound grain near by the $\mathrm{Cu}_{6} \mathrm{Sn}_{5}+\mathrm{Cu}_{3} \mathrm{Sn}$ two-phase layer, and Figure 2(d) represents that of a compound grain far from the two-phase layer. The compound grain in the $\mathrm{Sn}-\mathrm{Ni}$ alloy is originally $\mathrm{Ni}_{3} \mathrm{Sn}_{4}$ as shown in Fig. 2(d). In Fig. 2(c), however, $\mathrm{Ni}_{3} \mathrm{Sn}_{4}$ transforms into $(\mathrm{Cu}, \mathrm{Ni})_{6} \mathrm{Sn}_{5}$ by diffusion of $\mathrm{Cu}$ from the $\mathrm{Cu}$ specimen to the $\mathrm{Sn}-\mathrm{Ni}$ alloy across the compound layers. The $(\mathrm{Cu}, \mathrm{Ni})_{6} \mathrm{Sn}_{5}$ grains remain separately in Fig. 1(b) but adhere to the $\mathrm{Cu}_{6} \mathrm{Sn}_{5}$ layer in Fig. 1(a). In diffusion couples N1 and N2 annealed at $T=433-473 \mathrm{~K}$, the microstructure type of Fig. 1(a) was observed predominantly, and that of Fig. 1(b) was recognized partially.

Recently, the phase equilibria at the Sn-rich corner in the ternary $\mathrm{Sn}-\mathrm{Cu}-\mathrm{Ni}$ system were experimentally determined at 

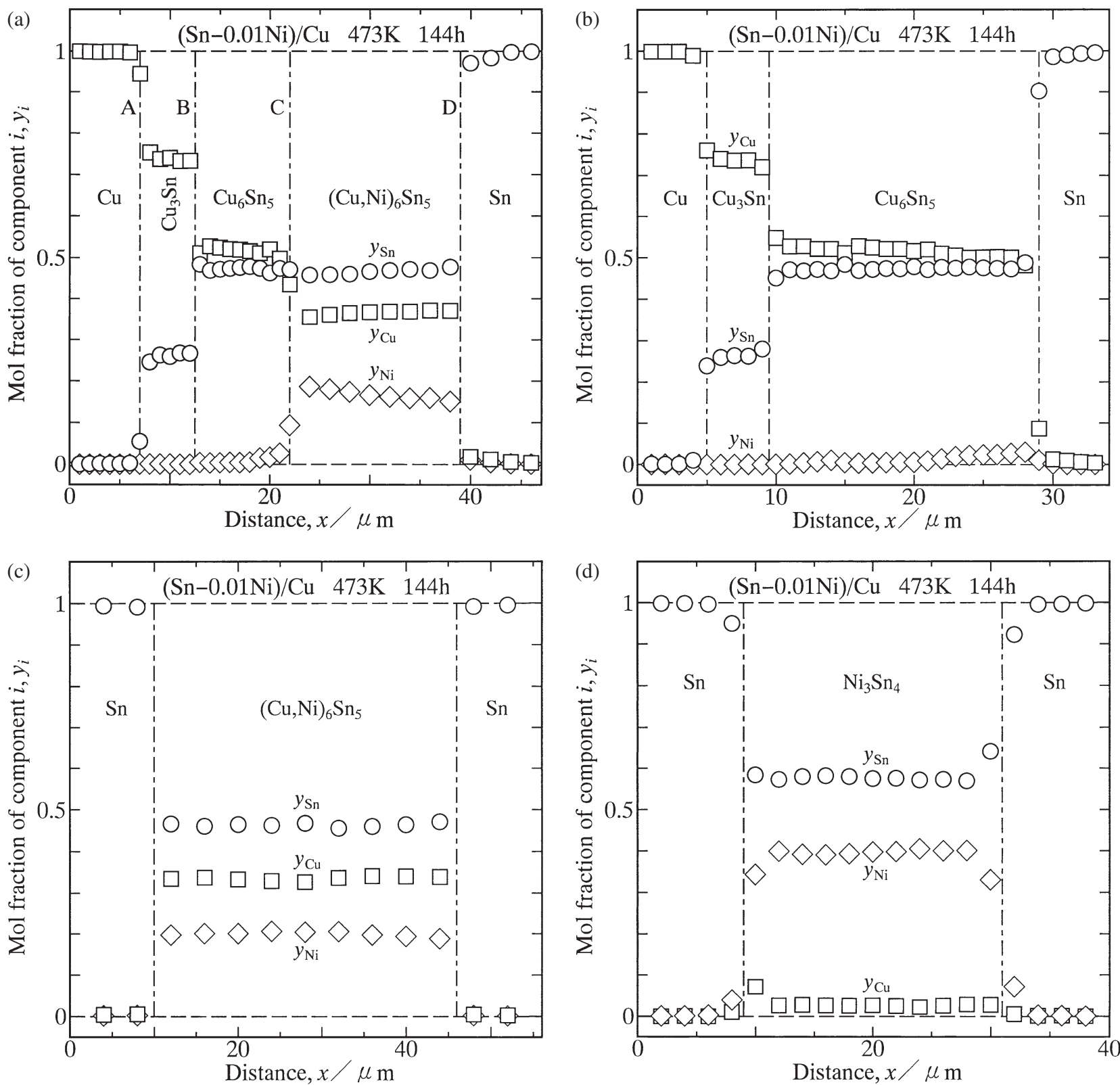

Fig. 2 Concentration profiles of $\mathrm{Sn}, \mathrm{Ni}$ and $\mathrm{Cu}$ across compound layers and compound grains for the diffusion couple shown in Fig. 1: (a) $(\mathrm{Cu}, \mathrm{Ni})_{6} \mathrm{Sn}_{5}, \mathrm{Cu}_{6} \mathrm{Sn}_{5}$ and $\mathrm{Cu}_{3} \mathrm{Sn}$ layers; (b) $\mathrm{Cu}_{6} \mathrm{Sn}_{5}$ and $\mathrm{Cu}_{3} \mathrm{Sn}$ layers; (c) $(\mathrm{Cu}, \mathrm{Ni})_{6} \mathrm{Sn}_{5}$ grain; and (d) $\mathrm{Ni}_{3} \mathrm{Sn}_{4}$ grain.

solid-state temperatures in a previous study. ${ }^{17)}$ The isothermal section at $T=473 \mathrm{~K}$ of the phase diagram in this ternary system is shown in Fig. 3. As can be seen, a three-phase equilibrium of $\mathrm{Sn}+(\mathrm{Cu}, \mathrm{Ni})_{6} \mathrm{Sn}_{5}+\mathrm{Ni}_{3} \mathrm{Sn}_{4}$ appears at this temperature. According to the tie-triangle of this three-phase equilibrium, the solubility $y_{\mathrm{Ni}}^{\mathrm{Cu}_{6} \mathrm{Sn}_{5}}$ of $\mathrm{Ni}$ in $\mathrm{Cu}_{6} \mathrm{Sn}_{5}$ is 0.224 , and that $y_{\mathrm{Cu}}^{\mathrm{Ni}_{3} \mathrm{Sn}_{4}}$ of $\mathrm{Cu}$ in $\mathrm{Ni}_{3} \mathrm{Sn}_{4}$ is $0.046 .{ }^{17)}$ Thus, $y_{\mathrm{Cu}}^{\mathrm{Ni}_{3} \mathrm{Sn}_{4}}$ is much smaller than $y_{\mathrm{Ni}}^{\mathrm{Cu}_{6} \mathrm{Sn}_{5}}$. Therefore, in Fig. $3, \mathrm{Cu}_{6} \mathrm{Sn}_{5}$ is described as $(\mathrm{Cu}, \mathrm{Ni})_{6} \mathrm{Sn}_{5}$, but $\mathrm{Ni}_{3} \mathrm{Sn}_{4}$ is merely expressed as $\mathrm{Ni}_{3} \mathrm{Sn}_{4}$. In Fig. 3, the concentration profiles for the two-phase layer and the $(\mathrm{Cu}, \mathrm{Ni})_{6} \mathrm{Sn}_{5}$ grain in Fig. 2 are plotted as diffusion paths with open circles and squares, respectively. For the two-phase layer, the open circles are located in the neighborhood of the binary $\mathrm{Sn}-\mathrm{Cu}$ side. In contrast, for the $(\mathrm{Cu}, \mathrm{Ni})_{6} \mathrm{Sn}_{5}$ grain, the open squares lie almost on the $(\mathrm{Cu}, \mathrm{Ni})_{6} \mathrm{Sn}_{5}$ corner of the three-phase tie-triangle. Thus, the concentration of $\mathrm{Ni}$ in the $(\mathrm{Cu}, \mathrm{Ni})_{6} \mathrm{Sn}_{5}$ grain reaches the solubility limit.

\subsection{Growth behavior of intermetallic layer}

As shown in Fig. 1(a), a multi-phase layer consisting of $(\mathrm{Cu}, \mathrm{Ni})_{6} \mathrm{Sn}_{5}, \mathrm{Cu}_{6} \mathrm{Sn}_{5}$ and $\mathrm{Cu}_{3} \mathrm{Sn}$ formed at the original ( $\mathrm{Sn}-$ $\mathrm{Ni} / \mathrm{Cu}$ interface in diffusion couples $\mathrm{N} 1$ and $\mathrm{N} 2$ due to isothermal annealing at $T=433-473 \mathrm{~K}$. Hereafter, the multiphase layer is merely called the intermetallic layer. From DICOM images, such as that indicated in Fig. 1(a), the area $A_{j}$ of the intermetallic layer corresponding to the partial length $w_{i}$ of the original $(\mathrm{Sn}-\mathrm{Ni}) / \mathrm{Cu}$ interface were measured for cross-section $j$. The sums $A$ and $w$ were obtained by the equations ${ }^{11)}$

$$
A=\sum_{j=1}^{m} A_{j}
$$

and

$$
w=\sum_{j=1}^{m} w_{j}
$$




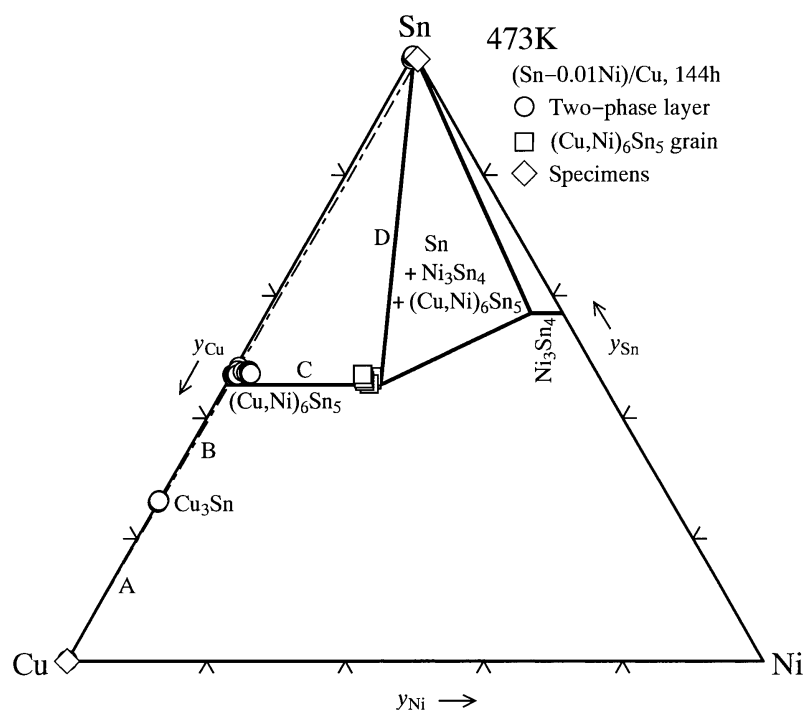

Fig. 3 Diffusion paths for the concentration profiles of the $\mathrm{Cu}_{6} \mathrm{Sn}_{5}$ and $\mathrm{Cu}_{3} \mathrm{Sn}$ layers and the $(\mathrm{Cu}, \mathrm{Ni})_{6} \mathrm{Sn}_{5}$ grain in Fig. 2 shown as open circles and squares, respectively.

from $A_{i}$ and $w_{i}$, respectively, where $w_{j}=422 \mu \mathrm{m}$ and $m \geq 5$. Using the values of $A$ and $w$, the total thickness $l$ of the intermetallic layer was evaluated at each annealing time $t$ as follows: ${ }^{11)}$

$$
l=\frac{A}{w} .
$$

The results of diffusion couples N0, ${ }^{11)} \mathrm{N} 1$ and N2 are shown as open circles, squares and rhombuses, respectively, in Fig. 4. Here, diffusion couple N0 stands for the $\mathrm{Sn} / \mathrm{Cu} / \mathrm{Sn}$ diffusion couple from a previous study. ${ }^{11)}$ Figure 4(a), 4(b) and 4(c) shows the results for $T=433,453$ and $473 \mathrm{~K}$, respectively. In this figure, the ordinate and the abscissa indicate the logarithms of $l$ and $t$, respectively. As can be seen, the thickness $l$ monotonically increases with increasing annealing time $t$. Furthermore, at $T=433-473 \mathrm{~K}$, the experimental points for each diffusion couple lie well on a straight line. Consequently, $l$ is expressed as a power function of $t$ as follows

$$
l=k\left(\frac{t}{t_{0}}\right)^{n}
$$

where $t_{0}$ is unit time, $1 \mathrm{~s}$, which is adopted to make the argument $t / t_{0}$ of the power function dimensionless. The proportionality coefficient $k$ has the same dimension as the thickness $l$, and the exponent $n$ is dimensionless. From the experimental points in Fig. $4, k$ and $n$ were evaluated by the least-squares method as indicated with various straight lines. The evaluated values of $k$ and $n$ are also shown in Fig. 4. According to the evaluation at $T=433-473 \mathrm{~K}$, the overall growth rate of the intermetallic layer considerably increases with increasing $\mathrm{Ni}$ concentration $y$ within the experimental annealing times.

\subsection{Growth behavior of two-phase layer}

According to Fig. 1(a), each compound is clearly distinguished in the intermetallic layer. From DICOM images, such as that shown in Fig. 1(a), the mean thickness $l_{i}$ of compound
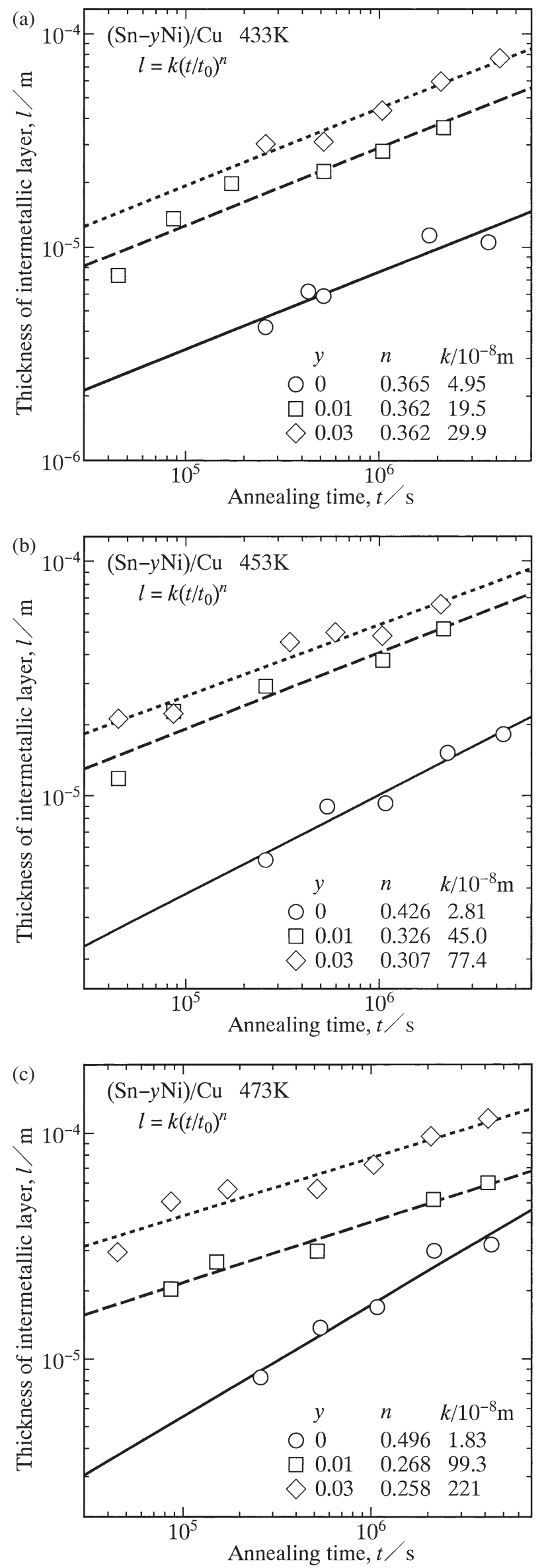

Fig. 4 The thickness $l$ in eq. (2) versus the annealing time $t$ for diffusion couples N0, ${ }^{11)} \mathrm{N} 1$ and $\mathrm{N} 2$ shown as open circles, squares and rhombuses, respectively: (a) $433 \mathrm{~K}$, (b) $453 \mathrm{~K}$ and (c) $473 \mathrm{~K}$. 
layer $i$ in the intermetallic layer was evaluated using the relationships similar to eqs. (1a), (1b) and (2), where $i=3$ and 6 for the $\mathrm{Cu}_{3} \mathrm{Sn}$ and $\mathrm{Cu}_{6} \mathrm{Sn}_{5}$ layers, respectively. The total thickness $l_{\mathrm{s}}$ of the $\mathrm{Cu}_{3} \mathrm{Sn}$ and $\mathrm{Cu}_{6} \mathrm{Sn}_{5}$ layers was calculated by the equation

$$
l_{\mathrm{s}}=l_{3}+l_{6}
$$

The $\mathrm{Cu}_{3} \mathrm{Sn}+\mathrm{Cu}_{6} \mathrm{Sn}_{5}$ two-phase layer excluding the $(\mathrm{Cu}, \mathrm{Ni})_{6} \mathrm{Sn}_{5}$ grains from the intermetallic layer is hereafter denominated the two-phase layer. The results of $l_{\mathrm{s}}, l_{6}$ and $l_{3}$ are shown as open circles, triangles and squares, respectively, in Figs. 5 and 6. In these figures, like Fig. 4, the ordinate and the abscissa indicate the logarithms of $l_{i}$ and $t$, respectively. Figure 5(a), 5(b) and 5(c) shows the results for diffusion couple N1 at $T=433,453$ and $473 \mathrm{~K}$, respectively, and Fig. 6(a), 6(b) and 6(c) represents those for diffusion couple N2 at $T=433,453$ and $473 \mathrm{~K}$, respectively. Although the open squares are slightly scattered due to small values of $l_{3}$, most of the open symbols are located well on the corresponding straight line. Therefore, we consider that $l_{i}$ is expressed as a power function of $t$ by the following equation of the same formula as eq. (3).

$$
l_{i}=k_{i}\left(\frac{t}{t_{0}}\right)^{n}
$$

From the experimental points in Figs. 5 and $6, k_{\mathrm{s}}$ and $n$ for $l_{\mathrm{s}}$ in eq. (5) were evaluated by the least-squares method as shown with solid lines. Since $l_{3}$ and $l_{6}$ are smaller than $l_{\mathrm{s}}$, the values of $k_{3}, k_{6}$ and $n$ for $l_{3}$ and $l_{6}$ cannot be estimated with the same reliability as those of $k_{\mathrm{s}}$ and $n$ for $l_{\mathrm{s}}$. Consequently, using the same value of $n$ as $l_{\mathrm{s}}, k_{3}$ and $k_{6}$ for $l_{3}$ and $l_{6}$ in eq. (5) were estimated from the open squares and triangles by the least-squares method as indicated with dashed and dotted lines, respectively. The values of $n, k_{\mathrm{s}}, k_{3}$ and $k_{6}$ are shown in Figs. 5 and 6 . Since $l_{3}$ is very small for diffusion couple N2 at $T=433 \mathrm{~K}, l_{3}$ and thus $l_{6}$ could not be reliably determined for most of the annealing times except the longest time of $t=1152 \mathrm{~h}\left(4.15 \times 10^{6} \mathrm{~s}\right)$ in Fig. 6(a). Therefore, $k_{3}$ and $k_{6}$ were not evaluated for diffusion couple $\mathrm{N} 2$ at $T=433 \mathrm{~K}$. As can be seen, $l_{3}$ is smaller than $l_{6}$ for diffusion couples $\mathrm{N} 1$ and N2 at $T=433-473 \mathrm{~K}$. Although the identical value of $n$ was adopted for each diffusion couple at each annealing temperature, $k_{3}, k_{6}$ and $k_{\mathrm{s}}$ were independently evaluated from the corresponding experimental points in Figs. 5 and 6 as mentioned earlier. As a result, the relationship $k_{\mathrm{s}}=k_{3}+k_{6}$ does not necessarily hold, even though equation (4) holds at each experimental annealing time.

The values of $l_{\mathrm{s}}$ in Figs. 5 and 6 are again plotted against the annealing time $t$ in Fig. 7. In this figure, the corresponding result of diffusion couple $\mathrm{N}^{11)}$ in Fig. 4 is also shown. Figure 7(a), 7(b) and 7(c) indicates the results for $T=433$, 453 and $473 \mathrm{~K}$, respectively, and open circles, squares and rhombuses represent the results of diffusion couples N0, ${ }^{11)}$ $\mathrm{N} 1$ and N2, respectively. Unlike $l$ in Fig. $4, l_{\mathrm{s}}$ rather gradually decreases with increasing $\mathrm{Ni}$ concentration $y$ within the experimental annealing times at each annealing temperature in Fig. 7. As mentioned in Section 3.1, $\mathrm{Ni}_{3} \mathrm{Sn}_{4}$ in the $\mathrm{Sn}-\mathrm{Ni}$ alloy transforms into $(\mathrm{Cu}, \mathrm{Ni})_{6} \mathrm{Sn}_{5}$ owing to diffusion of $\mathrm{Cu}$ from the $\mathrm{Cu}$ specimen to the $\mathrm{Sn}-\mathrm{Ni}$ alloy across the twophase layer. After transformation, $(\mathrm{Cu}, \mathrm{Ni})_{6} \mathrm{Sn}_{5}$ grains mainly
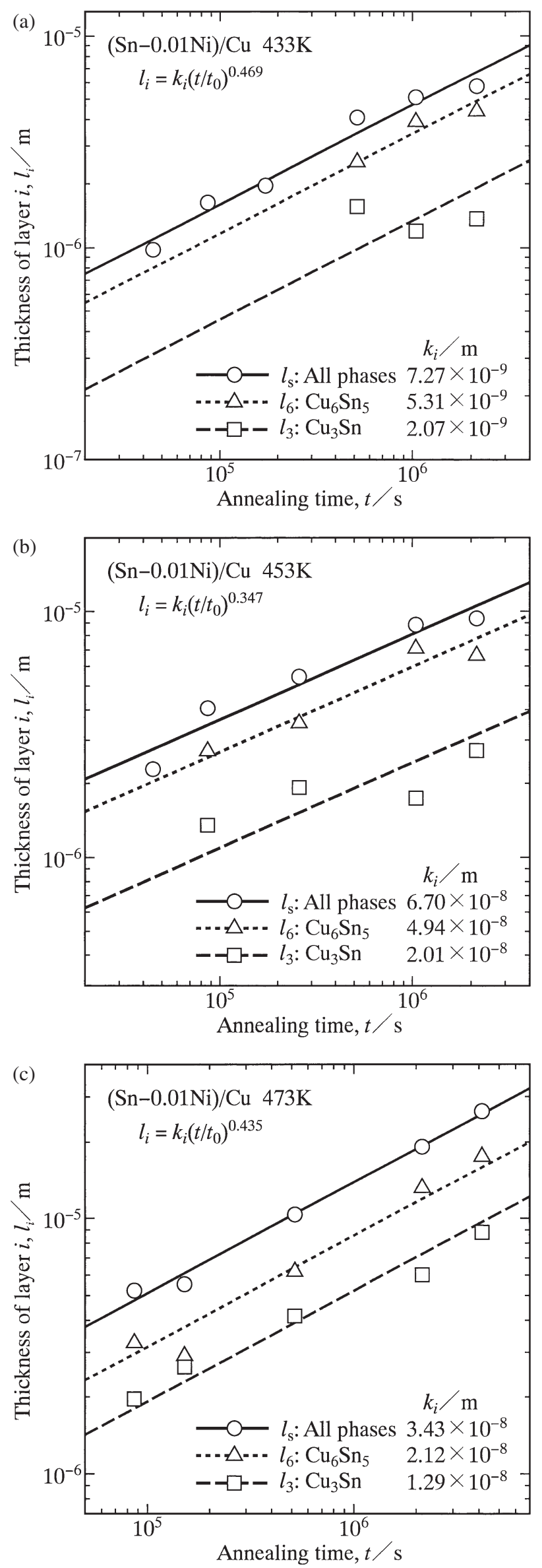

Fig. 5 The thicknesses $l_{\mathrm{s}}, l_{6}$ and $l_{3}$ in eq. (4) versus the annealing time $t$ for diffusion couple N1 shown as open circles, triangles and squares, respectively: (a) $433 \mathrm{~K}$, (b) $453 \mathrm{~K}$ and (c) $473 \mathrm{~K}$. 


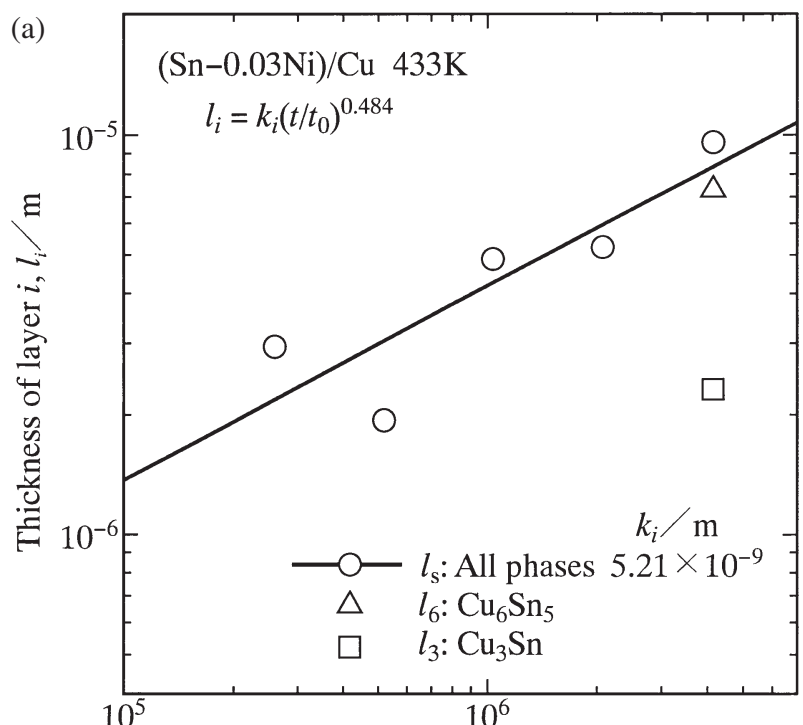

Annealing time, $t / \mathrm{s}$
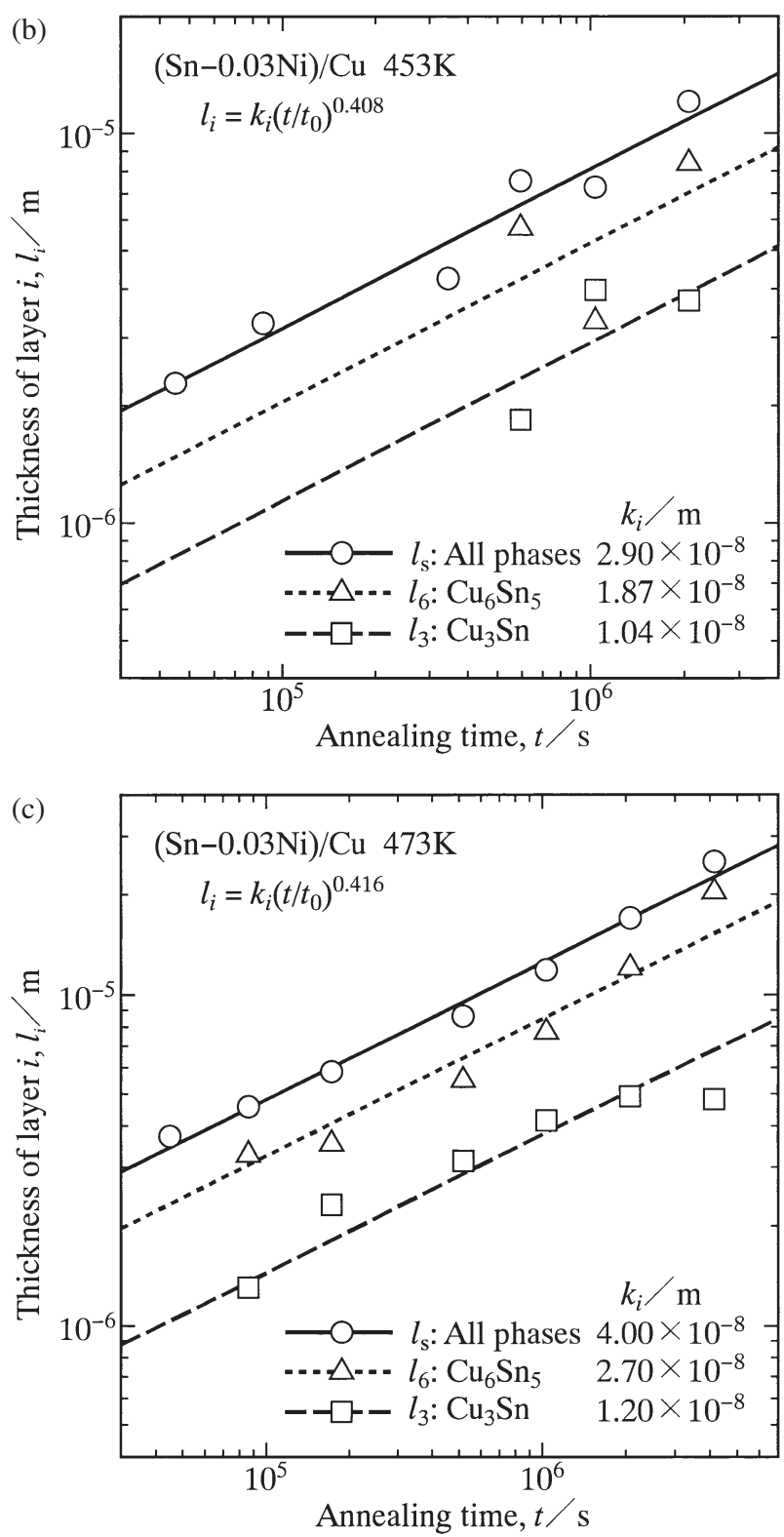

Fig. 6 The thicknesses $l_{\mathrm{s}}, l_{6}$ and $l_{3}$ in eq. (4) versus the annealing time $t$ for diffusion couple $\mathrm{N} 2$ shown as open circles, triangles and squares, respectively: (a) $433 \mathrm{~K}$, (b) $453 \mathrm{~K}$ and (c) $473 \mathrm{~K}$.
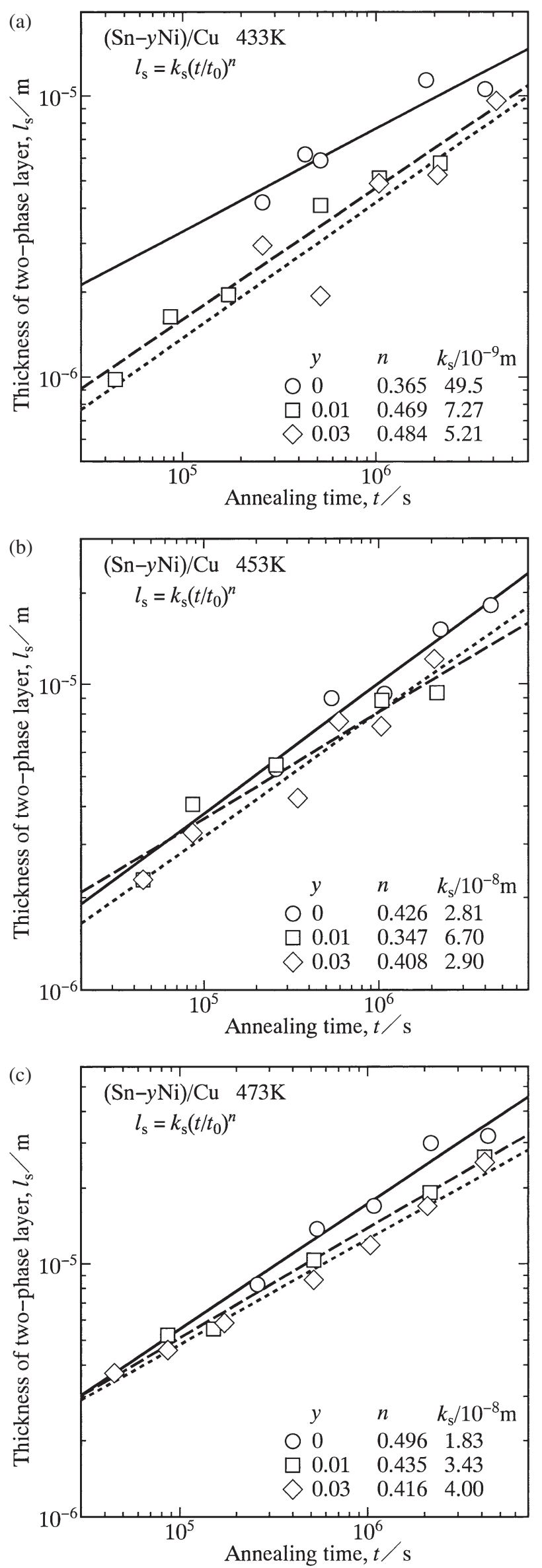

Fig. 7 The thickness $l_{\mathrm{s}}$ in eq. (4) versus the annealing time $t$ for diffusion couples N0, ${ }^{11)} \mathrm{N} 1$ and $\mathrm{N} 2$ shown as open circles, squares and rhombuses, respectively: (a) $433 \mathrm{~K}$, (b) $453 \mathrm{~K}$ and (c) $473 \mathrm{~K}$. 

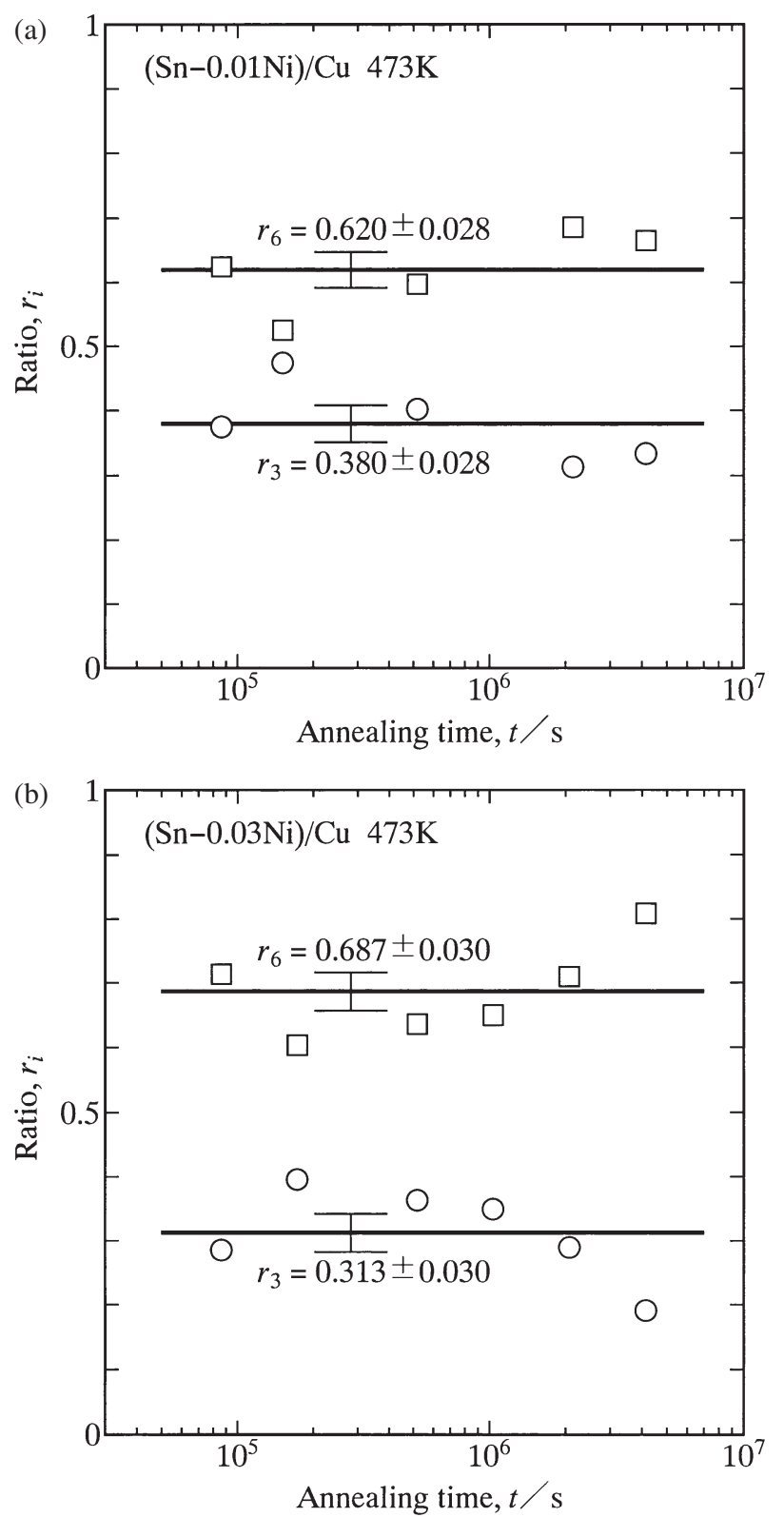

Fig. 8 The ratios $r_{3}$ and $r_{6}$ in eq. (6) versus the annealing time $t$ at $T=473 \mathrm{~K}$ shown as open circles and squares, respectively, with error bars: (a) diffusion couple N1, and (b) diffusion couple N2.

adhere to the $\mathrm{Cu}_{6} \mathrm{Sn}_{5}$ layer as shown in Fig. 1(a). The grain size is greater for the $(\mathrm{Cu}, \mathrm{Ni})_{6} \mathrm{Sn}_{5}$ grains adhered to the $\mathrm{Cu}_{6} \mathrm{Sn}_{5}$ layer than for those isolated in the $\mathrm{Sn}-\mathrm{Ni}$ alloy. According to the same mechanism as Ostwald ripening, ${ }^{18)}$ the coarse $(\mathrm{Cu}, \mathrm{Ni})_{6} \mathrm{Sn}_{5}$ grains grow, but the fine $(\mathrm{Cu}, \mathrm{Ni})_{6} \mathrm{Sn}_{5}$ grains shrink. As a consequence, the adhesion of $(\mathrm{Cu}, \mathrm{Ni})_{6} \mathrm{Sn}_{5}$ spontaneously proceeds during isothermal annealing. Although the adhesion directly contributes to the increase in the thickness $l$ of the intermetallic layer, it consumes the $\mathrm{Cu}$ atoms transported from the $\mathrm{Cu}$ specimen across the twophase layer as indicated in Fig. 2(a). The growth of the twophase layer will be decelerated by the consumption of the $\mathrm{Cu}$ atoms. This is the reason why the increase in the $\mathrm{Ni}$ concentration $y$ accelerates the overall growth of the intermetallic layer as shown in Fig. 4 but decelerates that of the two-phase layer as indicated in Fig. 7.

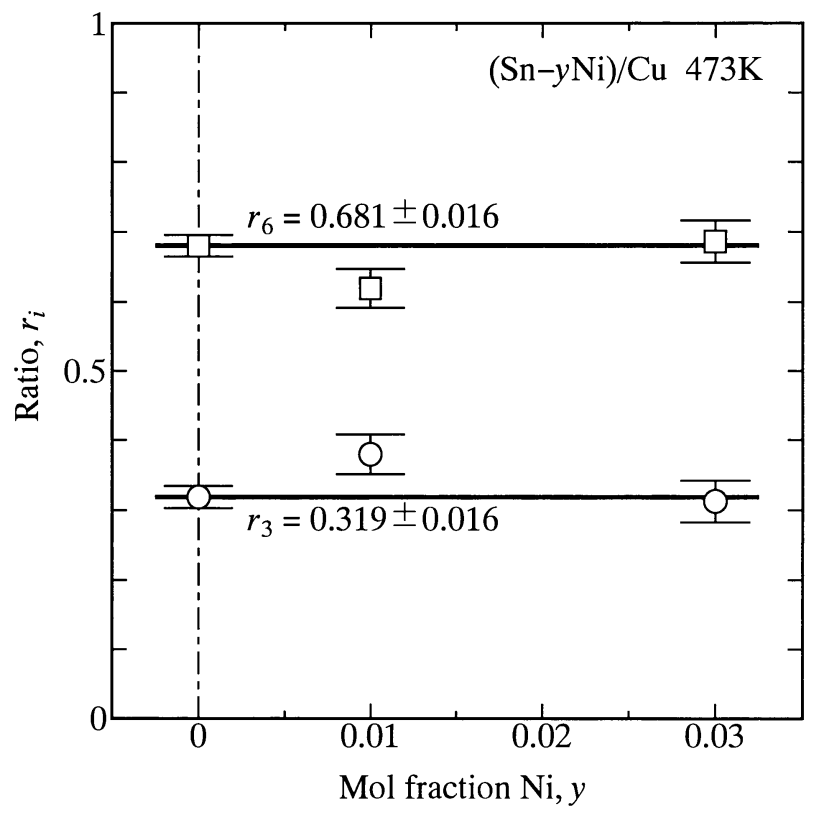

Fig. 9 The ratios $r_{3}$ and $r_{6}$ in eq. (6) versus the Ni mol fraction $y$ at $T=473 \mathrm{~K}$ shown as open circles and squares, respectively, with error bars. Horizontal solid lines indicate the mean values of $r_{3}$ and $r_{6}$ for $y=0$.

At each experimental annealing time, the ratio $r_{i}$ of the thickness $l_{i}$ to the total thickness $l_{\mathrm{s}}$ was evaluated by the equation

$$
r_{i}=\frac{l_{i}}{l_{\mathrm{s}}}
$$

The values of $r_{3}$ and $r_{6}$ at $T=473 \mathrm{~K}$ are plotted against the annealing time $t$ as open circles and squares, respectively, in Fig. 8. Figure 8(a) and 8(b) shows the results of diffusion couples $\mathrm{N} 1$ and N2, respectively. As indicated in Figs. 5 and $6, l_{3}$ is smaller than $l_{6}$. Consequently, $r_{3}$ is smaller than 0.5 , but $r_{6}$ is greater than 0.5 . Although the open symbols are slightly scattered in Fig. 8, there exists no systematic dependence of $r_{i}$ on $t$. Thus, we may consider that $r_{i}$ is constant independent of $t$ for each diffusion couple. The mean values of $r_{3}$ and $r_{6}$ were estimated from the open circles and squares, respectively, as shown as horizontal solid lines with error bars in Fig. 8. Here, the error bar indicates the standard error. The mean values of $r_{3}$ and $r_{6}$ are plotted against the Ni concentration $y$ as open circles and squares, respectively, with error bars in Fig. 9. In this figure, the corresponding results of $r_{3}$ and $r_{6}$ for $y=0^{11)}$ are also shown as open circles and squares, respectively, with error bars. Furthermore, their mean values for $y=0$ are emphasized with horizontal solid lines. As can be seen, the values of $r_{3}$ and $r_{6}$ at $y=0.03$ are almost equal to those of $r_{3}$ and $r_{6}$ at $y=0$, respectively, and there are no systematic dependencies of $r_{3}$ and $r_{6}$ on $y$. Thus, we may consider that $r_{3}$ and $r_{6}$ are constant independent of $y$. As a consequence, it is concluded that the addition of $\mathrm{Ni}$ into $\mathrm{Sn}$ up to 3 at\% slightly decelerates the overall growth of the $\mathrm{Cu}_{6} \mathrm{Sn}_{5}$ and $\mathrm{Cu}_{3} \mathrm{Sn}$ layers but hardly influences the ratio of their thicknesses.

\section{Conclusions}

The solid-state reactive diffusion in the $(\mathrm{Sn}-\mathrm{Ni}) / \mathrm{Cu}$ system was experimentally observed using the $(\mathrm{Sn}-\mathrm{Ni}) /$ 
$\mathrm{Cu} /(\mathrm{Sn}-\mathrm{Ni})$ diffusion couples with $\mathrm{Ni}$ mol fractions of $y=0.01$ and 0.03 . The diffusion couples were isothermally annealed at temperatures of $T=433,453$ and $473 \mathrm{~K}$ for various times up to $t=1152 \mathrm{~h}$. During annealing, the $\mathrm{Cu}_{6} \mathrm{Sn}_{5}+\mathrm{Cu}_{3} \mathrm{Sn}$ two-phase layer forms at the original ( $\mathrm{Sn}-$ $\mathrm{Ni} / \mathrm{Cu}$ interface in the diffusion couple, where the thickness is smaller for the $\mathrm{Cu}_{3} \mathrm{Sn}$ layer than for the $\mathrm{Cu}_{6} \mathrm{Sn}_{5}$ layer. The $\mathrm{Ni}_{3} \mathrm{Sn}_{4}$ grains in the $\mathrm{Sn}-\mathrm{Ni}$ alloy near by the two-phase layer transform into $(\mathrm{Cu}, \mathrm{Ni})_{6} \mathrm{Sn}_{5}$ and adhere to the $\mathrm{Cu}_{6} \mathrm{Sn}_{5}$ layer. Although the adhesion of $(\mathrm{Cu}, \mathrm{Ni})_{6} \mathrm{Sn}_{5}$ considerably accelerates the overall growth of the $\left(\mathrm{Cu}, \mathrm{Ni}_{6} \mathrm{Sn}_{5}+\mathrm{Cu}_{6} \mathrm{Sn}_{5}+\right.$ $\mathrm{Cu}_{3} \mathrm{Sn}$ layer, it slightly decelerates that of the $\mathrm{Cu}_{6} \mathrm{Sn}_{5}+$ $\mathrm{Cu}_{3} \mathrm{Sn}$ layer. The mean thickness of each compound layer is proportional to a power function of the annealing time. The addition of $\mathrm{Ni}$ into Sn within $y=0-0.03$ hardly influences the ratio between the thicknesses of the $\mathrm{Cu}_{6} \mathrm{Sn}_{5}$ and $\mathrm{Cu}_{3} \mathrm{Sn}$ layers at $T=433-473 \mathrm{~K}$.

\section{Acknowledgements}

The authors are grateful to Mr. K. Sakamoto and Mr. N. Kurokawa at Tyco Electronics AMP Co. Ltd., Japan for stimulating discussions. The present study was supported by the Iketani Science and Technology Foundation in Japan. The study was also partially supported by a Grant-in-Aid for Scientific Research from the Ministry of Education, Culture, Sports, Science and Technology of Japan.

\section{REFERENCES}

1) L. Zakraysek: Welding Res. Suppl. Nov. (1972) 536-541.

2) K. N. Tu: Acta Metall. 21 (1973) 347-354.

3) M. Onishi and H. Fujibuchi: Trans. JIM 16 (1975) 539-547.

4) H. N. Keller: IEEE Trans. Components Hybrids Manuf. Tech. CHMT2 (1979) 180-195.

5) H. N. Keller and J. M. Morabito: Surf. Interface Anal. 3 (1981) 16-22.

6) J. O. G. Parent, D. D. L. Chung and I. M. Bernstein: J. Mater. Sci. 23 (1988) 2564-2572.

7) A. J. Sunwoo, J. W. Morris, Jr. and G. K. Lucey, Jr.: Metall. Trans. A 23 (1992) 1323-1332.

8) P. T. Vianco, P. F. Hlava and A. L. Kilgo: J. Electron. Mater. 23 (1994) 583-594.

9) D. R. Frear and P. T. Vianco: Metall. Trans. A 25 (1994) 1509-1523.

10) S. Choi, T. R. Bieler, J. P. Lucas and K. N. Subramanian: J. Electron. Mater. 28 (1999) 1209-1215.

11) T. Takenaka, S. Kano, M. Kajihara, N. Kurokawa and K. Sakamoto: Mater. Sci. Eng. A 396 (2005) 115-123.

12) C. Wright: IEEE Trans. Parts, Hybrids, Packaging PHP-13 (1977) 202207.

13) H. N. Keller: IEEE Trans. Components, Hybrids, Manuf. Tech. CHMT-5 (1982) 408-419.

14) E. I.-B. Hannech and C. R. Hall: Mater. Sci. Tech. 8 (1992) 817-824.

15) G. Ghosh: Acta Mater. 48 (2000) 3719-3738.

16) M. Mita, M. Kajihara, N. Kurokawa and K. Sakamoto: Mater. Sci. Eng. A 403 (2005) 269-275.

17) W. Shinmei: Master Thesis, Tokyo Inst. Tech. (2013).

18) H. I. Aaronson, M. Enomoto and J. K. Lee: Mechanisms of Diffusional Phase Transformations in Metals and Alloys, (CRC Press, Boca Raton, 2010) pp. 482-487. 